\title{
Hair Cortisol as a Marker of Intergenerational Heritage of War? A Study of Veterans and Their Offspring
}

\author{
Ivone Castro-Vale ${ }^{1,2} \bowtie$, Elisabeth F.C. van Rossum ${ }^{3}$, Sabine M. Staufenbiel ${ }^{3}$, Milton Severo ${ }^{4}$, \\ Rui Mota-Cardoso', and Davide Carvalho ${ }^{2,5}$ \\ ${ }^{1}$ Department of Clinical Neurosciences and Mental Health, Faculty of Medicine, University of Porto, Porto, Portugal \\ 2i3S-Instituto de Investigação e Inovação em Saúde, Universidade do Porto, Porto, Portugal \\ ${ }^{3}$ Department of Internal Medicine, Division of Endocrinology, Erasmus MC, University Medical Center Rotterdam, Rotterdam, Netherlands \\ ${ }^{4}$ Department of Clinical Epidemiology, Predictive Medicine and Public Health and Department of Medical Education and Simulation, \\ Faculty of Medicine, University of Porto, Porto, Portugal \\ ${ }^{5}$ Department of Endocrinology, Diabetes and Metabolism, São João University Hospital Centre, Faculty of Medicine, University of Porto, Porto, Portugal
}

Objective Posttraumatic stress disorder (PTSD) has been associated with lower circulating cortisol levels in specific subgroups, which have also been found in the offspring of people with PTSD. The analysis of hair cortisol concentrations (HCC) is a recent methodology which is used to assess long-term systemic cortisol levels. We aimed to study veterans with war-related lifetime PTSD and their respective offspring with regards to HCC. We also studied the influence of lifetime major depressive disorder (MDD), war experiences, and childhood adversities on HCC in these groups.

Methods 31 male veterans with PTSD and 28 without PTSD and 69 adult offspring were studied. HCC were quantified by liquid chromatography tandem-mass spectrometry.

Results No differences in HCC were found between veterans with and without PTSD, or between their respective offspring. Veterans without MDD showed a positive association between total war exposure and HCC. Veterans reporting more frequent childhood physical abuse had lower HCC. Veterans-with-PTSD's offspring with MDD had increased HCC compared to offspring without MDD. Offspring's exposure to more frequent childhood physical abuse was negatively associated with HCC in those without MDD.

Conclusion HCC did not appear to constitute a marker of intergenerational heritage of war-related PTSD, except in the case of veteranswith-PTSD's offspring with MDD. Our data suggest that HCC is a marker of adult reported childhood physical abuse.

Psychiatry Investig 2020;17(10):976-986

Key Words Posttraumatic stress disorder, Hair cortisol, War veterans, Intergenerational transmission, Major depressive disorder, Childhood adversities.

\section{INTRODUCTION}

Posttraumatic stress disorder (PTSD) has been associated with altered regulation of the hypothalamic pituitary adrenal (HPA) axis, namely increased glucocorticoid (GC) sensitivity. ${ }^{1}$ This has been shown by the increased suppressive response of cortisol to the dexamethasone suppression test, and the in-

\footnotetext{
Received: June 4, 2020 Revised: July 24, 2020

Accepted: August 6, 2020

$\triangle$ Correspondence: Ivone Castro-Vale, MD, MSc, PhD

Department of Clinical Neurosciences and Mental Health, Faculty of Medicine, Universidade do Porto, Al. Prof. Hernâni Monteiro, Porto 4200-319, Portugal Tel: +351220426920, E-mail: ivonecastrovale@med.up.pt

(c) This is an Open Access article distributed under the terms of the Creative Commons Attribution Non-Commercial License (https://creativecommons.org/licenses/bync/4.0) which permits unrestricted non-commercial use, distribution, and reproduction in any medium, provided the original work is properly cited.
}

creased glucocorticoid receptor (GR) number. Accordingly, lower cortisol levels have been found in specific subgroups and time of day of assessment, such as morning cortisol (e.g., $\left.{ }^{2}\right)$. Time point measurements of cortisol in blood, saliva or urine, are all affected by pulsatile secretion, diurnal rhythm, and day to day variation. ${ }^{3}$ Levels of scalp hair cortisol constitute a longterm measurement which is not subject to such variations. ${ }^{4}$ Scalp hair cortisol has been shown to be a marker of longterm endogenous cortisol levels. ${ }^{4}$ One $\mathrm{cm}$ of hair corresponds to one month of hair growth. ${ }^{5}$ Therefore, hair cortisol concentrations (HCC) can be used to retrospectively study cortisol exposure from recent months, depending on the length of the hair segment. HCC have been shown to be a reliable method of measuring cortisol exposure and for reflecting the systemic effects of cortisol., ${ }^{4,6}$ 
In conditions of chronic stress, HCC have been shown to be increased (e.g., $\left.{ }^{7}\right)$. Conflicting results have been shown for subjects with PTSD. For example, Steudte et al. ${ }^{8}$ found that shortly after a traumatic event (TE), HCC were elevated in PTSD subjects when compared to traumatised controls, whereas Luo et al. ${ }^{9}$ found that immediately after the TE, HCC were higher in the traumatised group, either with, or without PTSD, when compared to the non-traumatised control group. In that study, more than six months after the TE, the PTSD group showed significantly lower HCC when compared to the non-PTSD traumatized group, however there were no differences when compared to the non-traumatised control group. A recent study did not show any associations between HCC and PTSD symptom severity, although a negative association with avoidance symptoms was observed..$^{10}$ Steudte et al. ${ }^{11}$ found no differences between PTSD subjects and trauma exposed controls, but significantly lower HCC in these TE exposed groups compared to a non-traumatised control group. Interestingly, these authors found negative correlations between HCC and severity of intrusion symptoms and also with time since traumatisation. Another study of the effects of traumatisation on HCC (PTSD subjects were excluded) found significantly higher levels in traumatised individuals when compared to controls, which declined 3.5 years after the trauma. ${ }^{12}$ Collectively, the previous studies all seem to show that HCC could be associated with the traumatised state of subjects, with specific PTSD phenotypes, and that it depends on the time that had elapsed since exposure to a TE and also the type of trauma. ${ }^{13}$ Some studies seem to support the idea that PTSD could be associated with lower HCC in female ${ }^{9,14}$ but not in male ${ }^{15}$ samples. Lower HCC have also been associated with childhood adversities. ${ }^{16}$

PTSD studies suggest an intergenerational transmission of neurobiological correlates of PTSD to offspring. ${ }^{17}$ Children of parents suffering from PTSD showed a significantly increased risk of developing PTSD and also other psychopathology. ${ }^{18-20}$ The neurobiological substrate for intergenerational transmission of PTSD to offspring seems to be related to HPA axis dysregulation, which is also found in their parents. ${ }^{21}$ The intergenerational transmission could be the result of inherited genetic factors, ${ }^{22,23}$ or as a consequence of veterans' war-related traumatic experiences and PTSD for the family, which are associated with interpersonal violence, affecting parenting. ${ }^{24-26}$ The highly adverse family emotional state prevalent when there is a veteran father with PTSD in the family dysregulates the HPA axis of the offspring. ${ }^{1727}$ Enhanced cortisol suppression after low dose dexamethasone was found in adult Holocaust survivors offspring (HSO) with PTSD, when compared with HSO without PTSD, or offspring of parents not exposed to the Holocaust. ${ }^{28}$ Lower plasma cortisol levels and lower 24 hour urinary cortisol excretion were also found to be associated with the offspring of Holocaust survivors with PTSD in other studies. ${ }^{20,29}$ These intergenerational effects have been found to be specifically associated with PTSD in mothers. ${ }^{18,29} \mathrm{Up}$ until now, no studies have evaluated an intergenerational influence of PTSD with respect to HCC.

PTSD is comorbid with major depressive disorder (MDD) in $52 \%$ of cases. ${ }^{30}$ PTSD and MDD have distinctive pathophysiologic mechanisms, ${ }^{31}$ particularly of opposing directions regarding GR function. MDD is associated with increased point measurements of cortisol, as well as increased HCC. ${ }^{32,33}$ It is also known that childhood trauma is a vulnerability factor for both PTSD and MDD ${ }^{20,34}$ and that it is associated with adult HPA alterations, including lower systemic cortisol, as reflected by time point, short-term, and hair measurements (e.g. $\left.{ }^{35,36}\right)$. Studies of cortisol in patients with PTSD should take MDD comorbidity into account.

The main objectives of this study were to evaluate HCC in veterans with, and without lifetime PTSD which was assessed 40 years after exposure, and also to investigate how these veterans are influenced by childhood adversities, war exposure, and MDD. Furthermore, associations of PTSD symptom subclasses with HCC were investigated. We also aimed to compare HCC in the offspring of veterans with lifetime PTSD versus the offspring of veterans without lifetime PTSD. Additionally, we studied whether offsprings HCC were influenced by childhood adversities and their fathers' war exposure and PTSD symptoms. We also studied the relation between depression and HCC in these specific study groups. In addition, we investigated whether veterans' $\mathrm{HCC}$ were associated with their offspring's HCC.

\section{METHODS}

\section{Participants and procedure}

The sampling procedure used two ways of selecting veterans: $75.0 \%$ were from an outpatient clinic of the Portuguese Disabled Veterans Association (ADFA), and 25.0\% were from three lists of veterans' companies dating back from war-time. All subjects were invited to participate if they fulfilled the warrelated Diagnostic and Statistical Manual of Mental Disorders, fourth edition (DSM-IV) criterion A of the diagnostic criteria for PTSD, and also if they had offspring. War veterans were excluded if they had neurologic, infectious, or any active medical diseases, or had taken oral glucocorticoids during the previous three months, or had a history of psychotic disorder, bipolar disorder, or any current substance use, or neurocognitive disorders. All veterans with lifetime PTSD were outpatients. Those without lifetime PTSD served as trauma-exposed controls, providing that they did not have any current psychiatric 
disorder. All interactions with the participants were performed by an experienced psychiatrist (the first author) who is also experienced in the treatment of war-veterans with and without PTSD. Furthermore, PTSD was diagnosed with the Portuguese version of the Clinician-Administered PTSD Scale and the other psychiatric disorders where investigated using the Portuguese version of the Structured Clinical Interview for DSM-IV axis I Scale as described in the next section. Sixty veterans [mean age 65.2 years $(\mathrm{SD}=3.4)$ ] agreed to participate, and 72 offspring [mean age 35.6 years $(\mathrm{SD}=4.8), 59.4 \%$ females] of 45 veterans also participated.

In this cross-sectional study, all participants received a written and verbal description of the study and gave their written informed consent. The study was approved by the Ethics Committee of Porto Faculty of Medicine (Comissão de Ética para a Saúde do Centro Hospitalar São João/Faculdade de Medicina da Universidade do Porto, IRB approval number: CES138/08).

\section{Clinical and psychological measures}

Sociodemographic data and clinical history were obtained. Socioeconomic status (SES) was measured using the Graffar Index, adapted for the Portuguese population. ${ }^{37,38}$ The Graffar Index classifies subjects into five classes, with 1 being the highest, and 5 the lowest SES class.

The Portuguese version of the Clinician-Administered PTSD Scale (CAPS ${ }^{39}$ was used to characterise the participants in relation to PTSD diagnosis, and also to investigate the type of TEs experienced. Lifetime PTSD was considered if participants had DSM-IV criteria, in accordance with Blake et al.s ${ }^{40}$ rule (frequency $\geq 1$ and intensity $\geq 2$ ) and a total CAPS score of 50 or more. The highest lifetime PTSD score was considered. Veterans were also grouped according to those who never had PTSD, veterans who had past PTSD, and veterans who have current PTSD with the previously mentioned criteria and rule. CAPS has shown high internal consistency ${ }^{39}$ and good correlations with other measures (e.g., ${ }^{41}$ ). CAPS items were also used to derive the five symptom subscales of the five-factor model of PTSD, as described in Horn et al. ${ }^{42}$ TEs were assessed with the CAPS Life Events Checklist (LEC), and subsequently checked for the DSM-IV A2 criterion, following the CAPS procedure. In order to determine participants' eligibility for the study, current and past psychiatric disorders were investigated, using the Portuguese version of the Structured Clinical Interview for DSM-IV axis I (SCID-I) disorders, ${ }^{43} \mathrm{ex}$ cept for the PTSD module.

Childhood trauma was investigated using the Portuguese version of the Childhood Trauma Questionnaire-Short Form (CTQ-SF). ${ }^{44,45}$ The CTQ-SF is a self-reporting measure, which has been validated in a Portuguese non-clinical sample (Cron- bach's alpha ranged from 0.84 , total score, to 0.47 , physical neglect). The questionnaire measures five different types of maltreatment during childhood and adolescence: emotional abuse, physical abuse, sexual abuse, emotional neglect, and physical neglect. In this study, we used each subscale and the total CTQSF score.

Finally, in order to characterise and quantify the war-related experiences of the participants, we built an instrument that was adapted to the specificities of the guerrilla war in which each veteran fought, using the War Exposure Questionnaire (WEQ; Castro-Vale and Maia, 2012, umpublished). This questionnaire was adapted from the "Severity of Exposure Index", which was used for the same purpose, and which had good internal consistency $(\alpha=0.79){ }^{46}$ The WEQ has 38 items, which enquires about eight different types of war-related experiences (war experiences, physical conditions, injury and disease, witnessing casualties amongst comrades, witnessing casualties amongst the enemy, witnessing casualties amongst civilians, actions on the enemy, and actions on civilians). Each type is the result of the sum of positively answered questions related to that subject, including: Have you been tortured? Have you participated in combat situations in which you could have lost your life? and Have you been sleepless for several days? The total sum gives a total WEQ score (ranging from 0 to 38). In our sample, the reliability (Cronbach's alpha) of the total WEQ score was 0.81 .

\section{Hair cortisol measurements}

All participants filled out a questionnaire concerning hair conditions. Around 100 strands of hair from the posterior vertex of the scalp were cut off as close to the scalp as possible. The hair was taped to a piece of paper, and the scalp end was then marked. The samples were stored at room temperature and protected from light exposure until the analyses were carried out.

Cortisol concentrations of hair segments from all subjects were analysed by liquid chromatography tandem-mass spectrometry (LC-MS/MS). The most proximal one to three $\mathrm{cm}$ of hair were used for analysis, as available. Based on the hair growth rate of one $\mathrm{cm}$ per month, these hair samples reflect the cumulative cortisol secretion of the previous one to three months. The sample preparation and analysis has been extensively described elsewhere. ${ }^{47}$ In short, the samples were cut into $1 \mathrm{~cm}$ segments, weighed, and then washed with $2 \mathrm{~mL}$ isopropanol during two minutes. The extraction of cortisol was achieved by overnight incubation with $1.4 \mathrm{~mL}$ methanol $(\mathrm{MeOH})$, and the presence of $100 \mu \mathrm{L}$ internal standard (cortisol-d4) for 18 hours, at $25^{\circ} \mathrm{C}$, whilst being gently shaken.

After extraction, the methanol was transferred to a glass vial and was then centrifuged at $4,500 \mathrm{rpm}$, at $4^{\circ} \mathrm{C}$ for 5 minutes. 
$1 \mathrm{~mL}$ of clear supernatant was then transferred into a new glass vial and this was evaporated under a soft stream of nitrogen at $50^{\circ} \mathrm{C}$. The dried samples were then reconstituted in $1 \mathrm{~mL} 2 \% \mathrm{MeOH}$, and vortexed at 2,000 rpm for $1 \mathrm{~min}$. The samples were further cleaned by solid phase extraction (SPE). Samples were evaporated at $50^{\circ} \mathrm{C}$ under a constant flow of nitrogen. Before injection, the dry residue was re-suspended in $30 \% \mathrm{MeOH}$. Steroid peak integrations were reviewed and were manually integrated by two independent persons when automated peak integration occurred incorrectly, or partially integrated peaks.

In the case of one veteran (who had PTSD in the past) and two offspring (both from the group of fathers with lifetime PTSD), HCC could not be measured. One of offspring (whose father had not lifetime PTSD) who had taken oral glucocorticoids during the previous three months was excluded. Fourteen participants (nine veterans and five offspring) had hair strands of less than three $\mathrm{cm}$ length, but at least $1 \mathrm{~cm}$, and were therefore included. No HCC differences were found between participants with three $\mathrm{cm}$ when compared to those with at least one $\mathrm{cm}$, neither when considered each group of veterans and offspring separately.

\section{Data analysis}

Continuous variables are described by mean (standard deviation, $\mathrm{SD}$ ), and nominal variables are described by relative frequencies and absolute frequencies. Initial veteran group comparisons and offspring group comparisons regarding socio-demographic and hair-related characteristics were performed, using independent samples t-Student tests for continuous variables, and chi-square or Fisher's exact tests for nominal variables.

In the scores of the CTQ-SF, some participants had missing answers to items and therefore we used simple mean imputation. Hair cortisol data were not normally distributed and logtransformations were applied to achieve a normal distribution. For descriptive purposes, geometrical mean HCC and $\mathrm{SD}$ are presented after anti-logarithmisation.

Group comparisons of HCC were performed with independent samples t-Student tests. ANOVA was used for comparisons between veterans who never had PTSD, veterans who had PTSD in the past, and veterans with current PTSD. The associations between the distinct continuous exposure variables and HCC were estimated, using linear regression models. The interaction between exposure variables and MDD with HCC was also studied, using linear regression models.

The statistical significance level was fixed at 0.05. Statistical analyses were performed with the IBM SPSS Statistics version 23 for Windows (IBM Corp., Armonk, NY, USA).

\section{RESULTS}

Characteristics of the total veteran sample $(n=59)$ included in the HCC analysis are described in Table 1. Groups were well-matched for socio-demographic and hair-related variables. No veterans had their hair treated, such as by dying, bleaching, permanent waving, or straightening. There were no differences between the offspring of veterans with and without PTSD concerning the use or not of hair treatments. Characteristics of the sample of veterans whose offspring was entered in the HCC analysis $(n=43)$ were identical to those whose offspring did not participate, or were excluded $(n=17)$. Table 2 shows the veterans' offspring characteristics. Offspring's groups according to lifetime PTSD diagnosis of their fathers were also well matched on socio-demographic and hair-related variables.

\section{HCC in war veterans}

HCC (pg/mg) were not different between the groups of veterans with $(n=31)$ and without $(n=28)$ lifetime PTSD $(M \pm S D$; $4.2 \pm 1.9$ vs. $4.4 \pm 1.8$; $\mathrm{p}=0.846$ ). Analysis of $\mathrm{HCC}$ between groups of veterans who never had PTSD, veterans who had past PTSD, and veterans who have current PTSD also did not show differences (non-PTSD, $\mathrm{n}=28: 4.35 \pm 1.79$; past-PTSD, $\mathrm{n}=18: 4.71 \pm$ 2.01; current-PTSD, $n=13$ : $3.67 \pm 1.79 ; \mathrm{p}=0.530$ ).

Veterans with lifetime PTSD did not show differences in HCC when we compared those with $(n=20)$ and without $(n=$ 11) lifetime MDD (Table 3, vertical analysis). The same applies to veterans without lifetime PTSD (four veterans with and 24 without lifetime MDD). Grouping veterans according to having $(n=24)$, or not having $(n=35)$ lifetime MDD, also showed no differences in HCC, in the case of veterans with lifetime MDD between those with $(n=20)$, or without $(n=4)$ lifetime PTSD and in the case of veterans without lifetime MDD between those with $(n=11)$, or without $(n=24)$ lifetime PTSD (Table 3, horizontal analysis).

In the total group of veterans, no associations between HCC and war exposure $(\beta=0.017 ; 95 \% \mathrm{CI}=-0.003,0.038)$ was observed (Table 4). In the group of veterans without lifetime MDD, significant positive associations were found between the HCC and total WEQ score $(\beta=0.032 ; 95 \% \mathrm{CI}=0.001,0.063)$, as well as having witnessed casualties amongst the enemy $(\beta=0.136$; $95 \% \mathrm{CI}=0.016,0.256)$. Veterans without lifetime MDD with more war exposure have higher HCC. With regards to childhood adversities, a significant inverse association between physical abuse and HCC was found $(\beta=-0.074 ; 95 \% \mathrm{CI}=$ $-0.141,-0.008)$. Veterans who had more childhood experiences of physical abuse had lower HCC. This effect did not depend on having lifetime MDD, or not (interaction effect of having or not lifetime MDD with childhood physical abuse 
Table 1. Characteristics of the total veteran sample

\begin{tabular}{|c|c|c|c|c|}
\hline & Total $(\mathrm{N}=59)$ & $\operatorname{PTSD}(\mathrm{N}=31)$ & Non-PTSD (N=28) & \\
\hline & Mean $\pm S D$ & Mean $\pm S D$ & Mean $\pm S D$ & $\mathrm{p}$ \\
\hline Age (years) & $65.2 \pm 3.4$ & $64.7 \pm 3.5$ & $65.8 \pm 3.3$ & 0.246 \\
\hline \multirow[t]{2}{*}{$\mathrm{BMI}\left(\mathrm{kg} / \mathrm{m}^{2}\right)$} & $27.7 \pm 3.1$ & $28.2 \pm 3.6$ & $27.2 \pm 2.4$ & 0.200 \\
\hline & $\mathrm{N}(\%)$ & $\mathrm{N}(\%)$ & $\mathrm{N}(\%)$ & \\
\hline Marital status & & & & 0.101 \\
\hline Married & $56(94.9)$ & $31(100)$ & $25(89.3)$ & \\
\hline Divorced or widowed & $3(5.1)$ & 0 & $3(10.7)$ & \\
\hline Graffar index & & & & 0.122 \\
\hline 2 & $8(13.6)$ & $2(6.5)$ & $6(21.4)$ & \\
\hline 3 & $37(62.7)$ & $19(61.3)$ & $18(64.3)$ & \\
\hline 4 & $14(23.7)$ & $10(32.3)$ & $4(14.3)$ & \\
\hline Disability* & $22(37.3)$ & $9(29.0)$ & $13(46.4)$ & 0.189 \\
\hline \multicolumn{5}{|l|}{ Hair characteristics } \\
\hline Natural hair colour & & & & 0.885 \\
\hline Black & $10(16.9)$ & $6(19.4)$ & $4(14.3)$ & \\
\hline Brown or red & $22(37.3)$ & $11(35.5)$ & $11(39.3)$ & \\
\hline Grey & $27(45.8)$ & $14(45.2)$ & $13(46.4)$ & \\
\hline Frequency of hair washing (per week) & & & & 1.000 \\
\hline$\leq 2$ & $16(27.1)$ & $8(25.8)$ & $8(28.6)$ & \\
\hline$\geq 3$ & $43(72.9)$ & $23(74.2)$ & $20(71.4)$ & \\
\hline Use of hair products ${ }^{\dagger}$ & $7(11.9)$ & $3(9.7)$ & $4(14.3)$ & 0.698 \\
\hline Smokers & $8(13.6)$ & $6(19.4)$ & $2(7.1)$ & 0.259 \\
\hline Daily alcohol consumption & $41(70.7)$ & $19(63.3)$ & $22(78.6)$ & 0.255 \\
\hline Regular medication & $54(91.5)$ & $30(96.8)$ & $24(85.7)$ & 0.180 \\
\hline Topical GC & $6(10.2)$ & $3(9.7)$ & $3(10.7)$ & 1.000 \\
\hline Psychoactive medication & $34(57.6)$ & $28(90.3)$ & $6(21.4)$ & $<0.001$ \\
\hline MDD lifetime & $24(40.7)$ & $20(64.5)$ & $4(14.3)$ & $<0.001$ \\
\hline
\end{tabular}

*disability refers to veterans with any war-related disabilities as considered by the Portuguese government, thair products concern spray, mousse, gel, and wax. PTSD: posttraumatic stress disorder, SD: standard deviation, BMI: body mass index, GC: glucocorticoids, MDD: major depressive disorder

on HCC, $\mathrm{p}=0.774)$.

\section{HCC in war veterans' offspring}

No associations were found between veterans HCC and their respective offspring's HCC ( $\beta=-0.010 ; 95 \% \mathrm{CI}=-0.209$, 0.188 ).

Offspring analysis showed no differences in the HCC between offspring of veterans with $(n=40)$, and offspring of veterans without $(n=29)$ lifetime PTSD $(M \pm S D$; with: $3.5 \pm 1.6$ vs. without: $3.7 \pm 1.8 ; \mathrm{p}=0.675$ ). Veterans-with-PTSD's offspring with $(n=15)$ lifetime MDD showed significantly higher HCC when compared to veterans-with-PTSD's offspring without $(\mathrm{n}=26)$ lifetime MDD ( $\mathrm{p}=0.038)$ (Table 3, vertical analysis). No associations were found between veterans' total war exposure score $(\beta=-0.006 ; 95 \% \mathrm{CI}=-0.022,0.011)$ and lifetime
CAPS' total score $(\beta=0.000 ; 95 \% \mathrm{CI}=-0.003,0.003)$ and their respective offspring's HCC (Table 5 ). In the group of offspring without lifetime MDD, a significant negative association between childhood physical abuse and HCC was found $(\beta=$ $-0.138 ; 95 \% \mathrm{CI}=-0.273,-0.003)$.

\section{DISCUSSION}

This study aimed to investigate the associations between war veterans' lifetime PTSD and HCC and intergenerational effects on the respective offspring. To our knowledge, this is the first study to address the intergenerational effects of veterans' PTSD on long-term cortisol levels, as measured by the hair analysis of the offspring.

In our sample, we did not find differences in HCC between 
Table 2. Characteristics of veterans' offspring according to the respective fathers' PTSD lifetime diagnosis

\begin{tabular}{|c|c|c|c|c|}
\hline & Total $(\mathrm{N}=69)$ & $\operatorname{PTSD}(\mathrm{N}=40)$ & Non-PTSD $(\mathrm{N}=29)$ & \\
\hline & Mean \pm SD & Mean $\pm S D$ & Mean $\pm S D$ & $\mathrm{p}$ \\
\hline Age (years) & $35.4 \pm 4.8$ & $35.2 \pm 4.9$ & $35.7 \pm 4.8$ & 0.681 \\
\hline \multirow[t]{2}{*}{$\operatorname{BMI}\left(\mathrm{kg} / \mathrm{m}^{2}\right)$} & $26.4 \pm 4.4$ & $26.5 \pm 4.1$ & $26.4 \pm 4.8$ & 0.917 \\
\hline & $\mathrm{N}(\%)$ & $\mathrm{N}(\%)$ & $\mathrm{N}(\%)$ & \\
\hline Sex & & & & 0.460 \\
\hline Female & $41(59.4)$ & $22(55.0)$ & $19(65.5)$ & \\
\hline Male & $28(40.3)$ & $18(45.0)$ & $10(34.5)$ & \\
\hline Marital status & & & & 0.375 \\
\hline Married/living together & $46(66.7)$ & $24(60.0)$ & $22(75.9)$ & \\
\hline Divorced & $5(7.2)$ & $4(10.0)$ & $1(3.4)$ & \\
\hline Single & $18(26.1)$ & $12(30.0)$ & $6(20.7)$ & \\
\hline Graffar index & & & & 0.198 \\
\hline 1 & $7(10.1)$ & $3(7.5)$ & $4(13.8)$ & \\
\hline 2 & $25(36.2)$ & $13(32.5)$ & $12(41.4)$ & \\
\hline 3 & $32(46.4)$ & $19(47.5)$ & $13(44.8)$ & \\
\hline 4 & $5(7.2)$ & $5(12.5)$ & 0 & \\
\hline \multicolumn{5}{|l|}{ Hair characteristics } \\
\hline Natural hair colour & & & & 1.000 \\
\hline Black & $5(7.2)$ & $3(7.5)$ & $2(6.9)$ & \\
\hline Brown & $60(87.0)$ & $35(87.5)$ & $25(86.2)$ & \\
\hline Blond & $4(5.8)$ & $2(5.0)$ & $2(6.9)$ & \\
\hline Frequency of hair washing (per week) & & & & 0.336 \\
\hline$\leq 2$ & $11(15.9)$ & $8(20.0)$ & $3(10.3)$ & \\
\hline$\geq 3$ & $58(84.1)$ & $32(80.0)$ & $26(89.7)$ & \\
\hline Use of hair products* & $17(24.6)$ & $9(22.5)$ & $8(27.6)$ & 0.778 \\
\hline Hair treatment ${ }^{\dagger}$ & $26(37.7)$ & $16(40.0)$ & $10(34.5)$ & 0.802 \\
\hline Smokers & $20(29.0)$ & $10(25.0)$ & $10(34.5)$ & 0.430 \\
\hline Daily alcohol consumption & $11(15.9)$ & $7(17.5)$ & $4(13.8)$ & 0.750 \\
\hline Regular medication & $32(46.4)$ & $19(47.5)$ & $13(44.8)$ & 1.000 \\
\hline Topical GC & $3(4.3)$ & $1(2.5)$ & $2(6.9)$ & 0.568 \\
\hline Psychoactive medication & $6(8.7)$ & $5(12.5)$ & $1(3.4)$ & 0.389 \\
\hline MDD, lifetime & $24(34.8)$ & $15(37.5)$ & $9(31.0)$ & 0.618 \\
\hline
\end{tabular}

*hair products concern spray, mousse, gel and wax, thair treatment concerns dying, bleaching and permanent waving and straightening. PTSD: posttraumatic stress disorder, SD: standard deviation, BMI: body mass index, GC: glucocorticoids, MDD: major depressive disorder

male veterans with, and without lifetime PTSD. This result is in accordance with previous studies, which reported no association between HCC and PTSD, ${ }^{11}$ and also in studies specifically carried out with samples of mainly men. ${ }^{15,48}$ Some studies have found HCC to be significantly lower in PTSD patients when compared with traumatised controls, but only in the case of female samples. ${ }^{9,14}$ Furthermore, previous studies of war-related trauma showed no associations between PTSD and HCC either. ${ }^{48,49}$ The fact that our study avoided inflating the discrimination between veterans with and without
PTSD, by excluding those with intermediate CAPS scores, may have contributed to the absence of differences in HCC between veterans with, and without lifetime PTSD. Veterans with, and without lifetime PTSD did not show differences in HCC between those who have lifetime MDD, and those who do not. Grouping veterans according to having lifetime MDD, or not, also showed no difference in HCC between those with, or without lifetime PTSD. The grouping of veterans depending on lifetime MDD was based on the assumption that both combat PTSD and MDD each have distinctive pathophysio- 
Table 3. Log HCC (pg/mg) mean (SD) comparisons between veterans with and without lifetime PTSD and their respective offspring, according to having MDD, or not

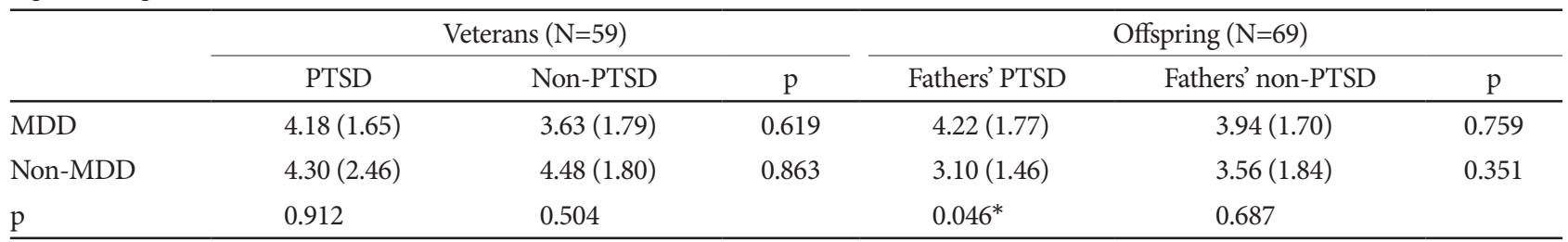

Geometrical mean \pm SD are shown. ${ }^{*} \mathrm{p}<0.05$. HCC: hair cortisol concentrations, SD: standard deviation, MDD: major depressive disorder, PTSD: posttraumatic stress disorder

Table 4. Veterans' associations between war exposure and childhood trauma and Log HCC (pg/mg) for the total sample and according to having lifetime MDD, or not

\begin{tabular}{|c|c|c|c|c|c|c|c|}
\hline & \multicolumn{2}{|c|}{ Total $(\mathrm{N}=59)$} & \multicolumn{2}{|c|}{$\operatorname{MDD}(\mathrm{N}=24)$} & \multicolumn{2}{|c|}{ Non-MDD (N=35) } & \multirow{2}{*}{$\frac{\text { Interaction }}{\mathrm{p}}$} \\
\hline & $\beta$ & $95 \% \mathrm{CI}$ & $\beta$ & $95 \% \mathrm{CI}$ & $\beta$ & $95 \% \mathrm{CI}$ & \\
\hline Total WEQ score & 0.017 & $-0.003,0.038$ & 0.003 & $-0.025,0.031$ & 0.032 & $0.001,0.063^{*}$ & 0.171 \\
\hline War experiences & 0.098 & $-0.032,0.229$ & 0.025 & $-0.154,0.203$ & 0.169 & $-0.026,0.363$ & 0.289 \\
\hline Physical conditions & 0.098 & $-0.023,0.220$ & 0.005 & $-0.188,0.199$ & 0.152 & $-0.012,0.316$ & 0.272 \\
\hline Injury and disease & 0.082 & $-0.036,0.199$ & 0.058 & $-0.110,0.226$ & 0.105 & $-0.065,0.274$ & 0.709 \\
\hline Witnessing casualties amongst comrades & 0.064 & $-0.040,0.168$ & 0.080 & $-0.041,0.201$ & 0.043 & $-0.130,0.216$ & 0.727 \\
\hline Witnessing casualties amongst the enemy & 0.075 & $-0.008,0.159$ & 0.005 & $-0.116,0.127$ & 0.136 & $0.016,0.256^{*}$ & 0.139 \\
\hline Witnessing casualties amongst civilians & -0.004 & $-0.089,0.081$ & -0.039 & $-0.147,0.070$ & 0.038 & $-0.100,0.176$ & 0.393 \\
\hline Actions on the enemy & 0.099 & $-0.030,0.228$ & 0.001 & $-0.173,0.175$ & 0.179 & $-0.010,0.367$ & 0.178 \\
\hline Actions on civilians & 0.005 & $-0.190,0.199$ & -0.065 & $-0.274,0.143$ & 0.178 & $-0.210,0.567$ & 0.255 \\
\hline CTQ-SF total & -0.005 & $-0.020,0.010$ & -0.007 & $-0.027,0.014$ & -0.003 & $-0.026,0.020$ & 0.814 \\
\hline Emotional abuse & -0.009 & $-0.061,0.043$ & -0.008 & $-0.078,0.061$ & -0.004 & $-0.087,0.079$ & 0.940 \\
\hline Emotional neglect & -0.004 & $-0.042,0.034$ & -0.020 & $-0.070,0.030$ & 0.009 & $-0.049,0.066$ & 0.472 \\
\hline Sexual abuse & -0.172 & $-0.417,0.073$ & -0.117 & $-0.613,0.379$ & -0.192 & $-0.501,0.116$ & 0.814 \\
\hline Physical abuse & -0.074 & $-0.141,-0.008^{*}$ & -0.078 & $-0.158,0.001$ & -0.069 & $-0.175,0.038$ & 0.886 \\
\hline Physical neglect & 0.005 & $-0.034,0.045$ & 0.013 & $-0.037,0.062$ & 0.001 & $-0.063,0.065$ & 0.774 \\
\hline
\end{tabular}

The $\beta$ and the 95\% CI that are shown are for two stratified models, one for MDD and the other for non-MDD. The p-value for the interaction is for a third model that puts together the two samples: the MDD and the non-MDD and adds the term for interaction. *p<0.05. HCC: hair cortisol concentrations, MDD: major depressive disorder, CI: confidence interval, WEQ: War Exposure Questionnaire, CTQ-SF: Childhood Trauma Questionnaire-Short Form

logic mechanisms, ${ }^{31}$ particularly of opposing directions regarding GR function. A previous meta-analytic study found no significant differences in daily cortisol output effect sizes for the TE, PTSD, and PTSD+MDD groups. ${ }^{2}$ Pinna et al. ${ }^{50}$ found increased salivary cortisol waking response in victims of intimate partner violence with MDD and also with both MDD and PTSD, but not with PTSD only, when compared to those with neither disorder. These authors conclude that comorbid depression could drive the relationship between PTSD and salivary cortisol response to waking, although the nature of the TE may also have had a strong influence. Since we measured HCC 40 years after war-related trauma, we may infer that the absence of differences in veterans' HCC might be attributed to the effect of time since trauma, which has been largely reported to be associated with decreased HCC when compared to those who were not exposed..$^{13}$ In future studies, it would be important to include a non-traumatised group. There is also a possibility that the absence of differences in veterans' HCC could have been influenced by treatments that veterans received over the years, either with psychotropic medications, or psychosocial interventions, although none had been in a structured psychotherapeutic intervention, such as the one described by Olff et al. ${ }^{51}$ which was found to be associated with cortisol increase in PTSD patients responders when controlling for depressive symptoms.

We did not observe any associations between war exposure and HCC in the total sample of veterans. One previous metaanalytic study found no associations of cortisol levels with trauma exposure. ${ }^{52}$ Recent studies have found lower plasma cortisol levels and specifically lower HCC to be associated with traumatic events. ${ }^{13,15}$ We found a positive association between war exposure and HCC after excluding veterans with 
Table 5. Offspring's associations between total war experiences and CAPS score of the father and childhood trauma and HCC (pg/mg) for the total sample and according to having lifetime MDD, or not

\begin{tabular}{|c|c|c|c|c|c|c|c|}
\hline & \multicolumn{2}{|c|}{ Total $(\mathrm{N}=69)$} & \multicolumn{2}{|c|}{$\operatorname{MDD}(\mathrm{N}=24)$} & \multicolumn{2}{|c|}{ Non-MDD $(\mathrm{N}=45)$} & \multirow{2}{*}{$\frac{\text { Interaction }}{\mathrm{p}}$} \\
\hline & $\beta$ & $95 \% \mathrm{CI}$ & $\beta$ & $95 \% \mathrm{CI}$ & $\beta$ & $95 \% \mathrm{CI}$ & \\
\hline Fathers' total WEQ score & -0.006 & $-0.022,0.011$ & -0.020 & $-0.058,0.019$ & -0.001 & $-0.019,0.018$ & 0.346 \\
\hline Fathers' total CAPS score & 0.000 & $-0.003,0.003$ & 0.001 & $-0.005,0.007$ & -0.001 & $-0.004,0.002$ & 0.554 \\
\hline CTQ-SF total & -0.001 & $-0.016,0.013$ & 0.005 & $-0.017,0.026$ & -0.020 & $-0.043,0.004$ & 0.119 \\
\hline Emotional abuse & 0.000 & $-0.039,0.039$ & 0.002 & $-0.058,0.062$ & -0.019 & $-0.075,0.037$ & 0.592 \\
\hline Emotional neglect & -0.004 & $-0.040,0.032$ & 0.015 & $-0.041,0.071$ & -0.028 & $-0.076,0.020$ & 0.231 \\
\hline Sexual abuse & 0.029 & $-0.025,0.083$ & 0.021 & $-0.041,0.083$ & -0.072 & $-0.531,0.387$ & 0.699 \\
\hline Physical abuse & -0.033 & $-0.112,0.045$ & -0.013 & $-0.121,0.096$ & -0.138 & $-0.273,-0.003^{*}$ & 0.147 \\
\hline Physical neglect & -0.056 & $-0.138,0.026$ & 0.022 & $-0.191,0.234$ & -0.072 & $-0.158,0.014$ & 0.372 \\
\hline
\end{tabular}

The $\beta$ and the 95\% CI that are shown are for two stratified models, one for MDD and the other for non-MDD. The p-value for the interaction is for a third model that puts together the two samples: the MDD and the non-MDD and adds the term for interaction. *p<0.05. HCC: hair cortisol concentrations, MDD: major depressive disorder, CI: confidence interval, WEQ: War Exposure Questionnaire, CAPS: Clinician-Administered Posttraumatic Stress Disorder Scale, CTQ-SF: Childhood Trauma Questionnaire-Short Form

lifetime MDD, which remained after adjusting for psychotropic use. Different results might be accounted by different methodologies, assessment after a long time since traumatization, and to the fact that we have only studied HCC association with a specific type of trauma.

With regards to childhood maltreatment, veterans who reported more frequent physical abuse had lower HCC. This association remained after adjusting for psychotropic use. In previous studies, cortisol measurements in bodily fluids, which reflect time point, or short-term measurements, have also been found to be associated with childhood adversities, in particular, physical abuse (e.g. . $^{20,35}$ ). Only a few studies have investigated the association between childhood adversities and long-term systemic cortisol, as measured by hair analysis. Hinkelmann et $a .^{36}$ reported a negative association between childhood trauma and HCC, which was also independent of depression. A recent meta-analysis found a negative moderate effect size association between childhood maltreatment and HCC. ${ }^{16}$ Similar to Steudte et al., ${ }^{11}$ we also found no association between total childhood trauma scores and HCC, probably due to methodology limitations. However, several studies increasingly support the association between early life stress and altered HPA axis function mediated by gene $\mathrm{x}$ environment interactions through mechanisms of epigenetic alterations. ${ }^{53,54}$ These epigenetic alterations have been associated with altered HCC and increased risk to develop PTSD. ${ }^{16,55}$ The association of childhood adversities and HCC could constitute one mechanism that moderates the association between HCC and PTSD. Further studies, particularly longitudinal ones, are warranted to better understand these effects.

Offspring of veterans with lifetime PTSD did not show differences in HCC when compared to those of veterans without lifetime PTSD. Even though no other studies have ad- dressed HCC in the offspring of parents with PTSD, lower plasma cortisol levels and lower 24 hour urinary cortisol excretion have been associated with the offspring of parents with PTSD (e.g. $\left.{ }^{29,56}\right)$. Accordingly, we did not find any association between veterans total lifetime PTSD symptoms, neither with total war exposure and respective offspring's HCC. War exposure intensity has been associated with child behaviour problems, ${ }^{57,58}$ however no studies have investigated associated HPA axis alterations in the children of war veterans. Most research studying cortisol in the intergenerational transmission of neurobiological correlates of PTSD studied HSO, using plasma or urine. These studies found decreased cortisol levels in the HSO of parents with PTSD, and particularly of mothers, when compared to parents without PTSD. ${ }^{17,59}$ Our study differs with respect to a different methodology, as we did not include mothers, studied a different population, and used HCC, which reflected long-term, rather than short-term cortisol levels. ${ }^{4}$ In this study, offspring of veterans with lifetime PTSD that have lifetime MDD had significantly higher HCC when compared with those without lifetime MDD. This result is in accordance with the theory of depression relating to an altered HPA axis function in the opposite direction of PTSD..$^{60}$ In fact, increased HCC have been previously found in depressed patients. ${ }^{32}$ Increased point measurements of cortisol, and enhanced cortisol stress reactivity have also been found in cases of depression. ${ }^{33,61}$

Offspring without lifetime MDD showed a negative association between childhood physical abuse and HCC. As mentioned above, childhood adversities have previously been related with alterations of HPA axis functioning, particularly those with lower cortisol levels (e.g., ${ }^{16,61,62}$ ). Specifically, physical abuse has been found to be associated with a blunted salivary cortisol response to psychosocial stress in a non-clinical 
sample ${ }^{62}$ and with lower cortisol plasma levels in personality disorder patients. ${ }^{35}$ Hinkelmann et al. ${ }^{36}$ and Suzuki et al. ${ }^{61}$ found that the HPA axis alterations associated with childhood adversities did not depend on depression. In our study, we only found an association in the case of offspring without depression. This result is consistent with that of their fathers, who showed a negative association between childhood physical abuse and HCC, which did not depend on the presence of depression. The absence of an association between fathers' and offspring's HCC reflects the complexity of inheritance on the regulation of HPA axis functioning.

Some important aspects of this study need to be highlighted, such us: All the war veterans were evaluated with the gold standard instrument to diagnose PTSD, the CAPS; both veterans and their offspring were objectively and directly evaluated. Moreover, this study did not inflate the discrimination between veterans with, and without PTSD, as we did not exclude veterans with intermediate CAPS scores.

One limitation of this study is the cross-sectional nature of the design, which does not allow for drawing causal inferences from our findings. The small sample size warrants future studies to confirm our results, which should include larger samples. The fact that only men in the group of parents were studied does not allow for generalising the results for females. The same applies to the generalisation of TE, as the index trauma was only combat-related. It would be important to have a nottrauma-exposed group to observe the differences that could be attributed to exposure. Since PTSD was studied as a categorical variable, when we performed a sensitivity analysis no associations were found between HCC and CAPS total and symptom subscales scores, considering the DSM-IV threefactor model and the five-factor model, even after adjusting for lifetime MDD in the total group of veterans. This could also be attributed to a confounding effect. In the statistical analysis, we did not consider dependency by family. However, we estimated the dependency of HCC by family using interclass correlation and the value was zero, meaning that we can ignore the dependency by family for this analysis. We did not study the modifying role of the offspring's mother, which is another limitation to the understanding of what conditions were really inherited from veterans. We cannot rule out that our results may be explained by a type I error, as we did not correct for multiple-testing, considering the resulting risk of increase of type II error in this study.

In summary, no differences in HCC were found between veterans with and without lifetime PTSD, neither between their respective offspring. This could be attributed to the sample of veterans being exclusively male. Veterans-with-PTSD's offspring with lifetime MDD showed increased HCC, when compared to veterans-with-PTSD's offspring without lifetime
MDD. Veterans without lifetime MDD showed a positive association between total war exposure and witnessing casualties amongst the enemy, and HCC. Veterans reporting more childhood physical abuse had lower HCC, which was an effect that did not depend on the presence of lifetime MDD. No associations were found between offspring's HCC and their fathers' HCC, neither war exposure, nor total CAPS score. Offspring's childhood physical abuse was negatively associated with HCC in those without lifetime MDD. Accordingly, we can conclude from this study that HCC do not seem to constitute a marker of intergenerational heritage of war-related PTSD, except in the case of offspring with lifetime MDD of veterans with PTSD. However, our data suggest that HCC is a marker of adult reported childhood physical abuse.

\section{Acknowledgments}

We thank the Portuguese Disabled Veterans Association: Associação dos Deficientes das Forças Armadas (ADFA) for its help in selecting the sample. We also thank Sara Rocha and Catarina Gomes for their assistance.

The second author (EFCvR) has been supported by an Erasmus MC research fellowship, and the Netherlands Brain Foundation (grant number F2011(1)-12), and is currently supported by a a Vidi grant from the Netherlands Organization of Scientific Research NWO (grant number: 91716453).

This work was partially supported by the Associação dos Amigos do Serviço de Endocrinologia do Hospital de São João.

\section{Conflicts of Interest}

The authors have no potential conflicts of interest to disclose.

\section{Author Contributions}

Conceptualization: Ivone Castro-Vale, Rui Mota-Cardoso, Elisabeth F.C. van Rossum, Davide Carvalho. Data curation: Ivone Castro-Vale. Methodology: Ivone Castro-Vale, Sabine Staufenbiel. Formal analysis: Milton Severo, Ivone Castro-Vale. Writing_original draft: Ivone Castro-Vale. Writing_review \& editing: Ivone Castro-Vale, Elisabeth F.C. van Rossum, Sabine M. Staufenbiel, Milton Severo, Rui Mota-Cardoso, Davide Carvalho.

\section{ORCID iDs}

Ivone Castro-Vale

Elisabeth F.C. van Rossum

Sabine M. Staufenbiel

Milton Severo

Rui Mota-Cardoso

Davide Carvalho https://orcid.org/0000-0002-5343-0229 https://orcid.org/0000-0003-0120-4913 https://orcid.org/0000-0001-7208-7844 https://orcid.org/0000-0002-5787-4871 https://orcid.org/0000-0001-9597-5668 https://orcid.org/0000-0002-3156-3741

\section{REFERENCES}

1. Daskalakis NP, Lehrner A, Yehuda R. Endocrine aspects of post-traumatic stress disorder and implications for diagnosis and treatment. Endocrinol Metab Clin North Am 2013;42:503-513.

2. Morris MC, Compas BE, Garber J. Relations among posttraumatic stress disorder, comorbid major depression, and HPA function: a systematic review and meta-analysis. Clin Psychol Rev 2012;32:301-315.

3. Lightman SL, Conway-Campbell BL. The crucial role of pulsatile activity of the HPA axis for continuous dynamic equilibration. Nat Rev Neurosci 2010;11:710-718.

4. Manenschijn L, Koper JW, Lamberts SW, van Rossum EF. Evaluation of a method to measure long term cortisol levels. Steroids 2011;76:10321036.

5. Pragst F, Balikova MA. State of the art in hair analysis for detection of 
drug and alcohol abuse. Clin Chim Acta 2006;370:17-49.

6. Stalder T, Kirschbaum C. Analysis of cortisol in hair--state of the art and future directions. Brain Behav Immun 2012;26:1019-1029.

7. Stalder T, Tietze A, Steudte S, Alexander N, Dettenborn L, Kirschbaum C. Elevated hair cortisol levels in chronically stressed dementia caregivers. Psychoneuroendocrinology 2014;47:26-30.

8. Steudte S, Kolassa IT, Stalder T, Pfeiffer A, Kirschbaum C, Elbert T. Increased cortisol concentrations in hair of severely traumatized Ugandan individuals with PTSD. Psychoneuroendocrinology 2011;36:1193-1200.

9. Luo H, Hu X, Liu X, Ma X, Guo W, Qiu C, et al. Hair cortisol level as a biomarker for altered hypothalamic-pituitary-adrenal activity in female adolescents with posttraumatic stress disorder after the 2008 Wenchuan earthquake. Biol Psychiatry 2012;72:65-69.

10. Wang L, Cao C, Wang W, Xu H, Zhang J, Deng H, et al. Linking hair cortisol levels to phenotypic heterogeneity of posttraumatic stress symptoms in highly traumatized chinese women. Biol Psychiatry 2015;77:e21e22.

11. Steudte S, Kirschbaum C, Gao W, Alexander N, Schonfeld S, Hoyer J, et al. Hair cortisol as a biomarker of traumatization in healthy individuals and posttraumatic stress disorder patients. Biol Psychiatry 2013;74: 639646.

12. Gao W, Zhong P, Xie Q, Wang H, Jin J, Deng H, et al. Temporal features of elevated hair cortisol among earthquake survivors. Psychophysiology 2014;51:319-326.

13. Steudte-Schmiedgen S, Kirschbaum C, Alexander N, Stalder T. An integrative model linking traumatization, cortisol dysregulation and posttraumatic stress disorder: Insight from recent hair cortisol findings. Neurosci Biobehav Rev 2016;69:124-135.

14. van Zuiden M, Savas M, Koch SBJ, Nawijn L, Staufenbiel SM, Frijling $\mathrm{JL}$, et al. Associations among hair cortisol concentrations, posttraumatic stress disorder status, and amygdala reactivity to negative affective stimuli in female police officers. J Trauma Stress 2019;32:238-248.

15. Sierau S, Glaesmer H, Klucken T, Stalder T. Hair cortisol, lifetime traumatic experiences and psychopathology in unaccompanied refugee minors. Psychoneuroendocrinology 2019;104:191-194.

16. Khoury JE, Bosquet Enlow M, Plamondon A, Lyons-Ruth K. The association between adversity and hair cortisol levels in humans: A metaanalysis. Psychoneuroendocrinology 2019;103:104-117.

17. Leen-Feldner EW, Feldner MT, Knapp A, Bunaciu L, Blumenthal H, Amstadter AB. Offspring psychological and biological correlates of parental posttraumatic stress: review of the literature and research agenda. Clin Psychol Rev 2013;33:1106-1133.

18. Yehuda R, Bell A, Bierer LM, Schmeidler J. Maternal, not paternal, PTSD is related to increased risk for PTSD in offspring of Holocaust survivors. J Psychiatr Res 2008;42:1104-1111.

19. Vaage AB, Thomsen PH, Rousseau C, Wentzel-Larsen T, Ta TV, Hauff E. Paternal predictors of the mental health of children of Vietnamese refugees. Child Adolesc Psychiatry Ment Health 2011;5:2.

20. Yehuda R, Halligan SL, Grossman R. Childhood trauma and risk for PTSD: relationship to intergenerational effects of trauma, parental PTSD, and cortisol excretion. Dev Psychopathol 2001;13:733-753.

21. Yehuda R, Engel SM, Brand SR, Seckl J, Marcus SM, Berkowitz GS. Transgenerational effects of posttraumatic stress disorder in babies of mothers exposed to the World Trade Center attacks during pregnancy. J Clin Endocrinol Metab 2005;90:4115-4118.

22. Yehuda R, Flory JD, Bierer LM, Henn-Haase C, Lehrner A, Desarnaud $\mathrm{F}$, et al. Lower methylation of glucocorticoid receptor gene promoter $1 \mathrm{~F}$ in peripheral blood of veterans with posttraumatic stress disorder. Biol Psychiatry 2015;77:356-364.

23. Yehuda R, Daskalakis NP, Lehrner A, Desarnaud F, Bader HN, Makotkine I, et al. Influences of maternal and paternal PTSD on epigenetic regulation of the glucocorticoid receptor gene in Holocaust survivor offspring. Am J Psychiatry 2014;171:872-880.

24. Beckham JC, Feldman ME, Kirby AC, Hertzberg MA, Moore SD. Interpersonal violence and its correlates in Vietnam veterans with chronic posttraumatic stress disorder. J Clin Psychol 1997;53:859-869.

25. Gold JI, Taft CT, Keehn MG, King DW, King LA, Samper RE. PTSD symptom severity and family adjustment among female Vietnam veterans. Mil Psychol 2007;19:71-81.

26. Leen-Feldner EW, Feldner MT, Bunaciu L, Blumenthal H. Associations between parental posttraumatic stress disorder and both offspring internalizing problems and parental aggression within the National Comorbidity Survey-Replication. J Anxiety Disord 2011;25:169-175.

27. Bridgett DJ, Burt NM, Edwards ES, Deater-Deckard K. Intergenerational transmission of self-regulation: a multidisciplinary review and integrative conceptual framework. Psychol Bull 2015;141:602-654.

28. Yehuda R, Blair W, Labinsky E, Bierer LM. Effects of parental PTSD on the cortisol response to dexamethasone administration in their adult offspring. Am J Psychiatry 2007;164:163-166.

29. Yehuda R, Teicher MH, Seckl JR, Grossman RA, Morris A, Bierer LM. Parental posttraumatic stress disorder as a vulnerability factor for low cortisol trait in offspring of holocaust survivors. Arch Gen Psychiatry 2007;64:1040-1048.

30. Rytwinski NK, Scur MD, Feeny NC, Youngstrom EA. The co-occurrence of major depressive disorder among individuals with posttraumatic stress disorder: a meta-analysis. J Trauma Stress 2013;26:299-309.

31. Stander VA, Thomsen CJ, Highfill-McRoy RM. Etiology of depression comorbidity in combat-related PTSD: a review of the literature. Clin Psychol Rev 2014;34:87-98.

32. Dettenborn L, Muhtz C, Skoluda N, Stalder T, Steudte S, Hinkelmann $\mathrm{K}$, et al. Introducing a novel method to assess cumulative steroid concentrations: increased hair cortisol concentrations over 6 months in medicated patients with depression. Stress 2012;15:348-353.

33. Vreeburg SA, Hoogendijk WJ, van Pelt J, Derijk RH, Verhagen JC, van Dyck R, et al. Major depressive disorder and hypothalamic-pituitaryadrenal axis activity: results from a large cohort study. Arch Gen Psychiatry 2009;66:617-626.

34. Mandelli L, Petrelli C, Serretti A. The role of specific early trauma in adult depression: a meta-analysis of published literature. Childhood trauma and adult depression. Eur Psychiatry 2015;30:665-680.

35. Flory JD, Yehuda R, Grossman R, New AS, Mitropoulou V, Siever LJ. Childhood trauma and basal cortisol in people with personality disorders. Compr Psychiatry 2009;50:34-37.

36. Hinkelmann K, Muhtz C, Dettenborn L, Agorastos A, Wingenfeld K, Spitzer C, et al. Association between childhood trauma and low hair cortisol in depressed patients and healthy control subjects. Biol Psychiatry 2013;74:e15-e17.

37. Graffar M. Une methode de classification sociales dechantillons de population. Courrier 1956;6:445-459.

38. Costa AMB, Leitão FR, Santos J, Pinto JV, Fino MN. Formulários utilizados na caracterização do aluno no seu contexto familiar, escolar e social e na elaboração do programa educativo. Currículos funcionais (Vol. 2). Lisboa: Instituto de Inovação Educacional,1996, p.11-60.

39. Blake DD, Weathers FW, Nagy LM, Kaloupek DG, Gusman FD, Charney DS, et al. The development of a Clinician-Administered PTSD Scale. J Trauma Stress 1995;8:75-90.

40. Blake DD, Weathers F, Nagy LM, Kaloupek DG, Klauminzer G, Charney $\mathrm{D}$, et al. A clinician rating scale for assessing current and lifetime PTSD: the CAPS-1. Behav Ther 1990;13:187-188.

41. Blanchard EB, Jones-Alexander J, Buckley TC, Forneris CA. Psychometric properties of the PTSD Checklist (PCL). Behav Res Ther 1996; 34:669-673.

42. Horn CA, Pietrzak RH, Corsi-Travali S, Neumeister A. Linking plasma cortisol levels to phenotypic heterogeneity of posttraumatic stress symptomatology. Psychoneuroendocrinology 2014;39:88-93.

43. First MB, Spitzer RL, Gibbon M, Williams JBW. Structured Clinical Interview for DSM-IV Axis I Disorders, Clinician Version (SCID-CV). Washington, D.C.: American Psychiatric Press, Inc.; 1996.

44. Bernstein DP, Stein JA, Newcomb MD, Walker E, Pogge D, Ahluvalia T, et al. Development and validation of a brief screening version of the 
Childhood Trauma Questionnaire. Child Abuse Negl 2003;27:169-190.

45. Dias A, Sales L, Carvalho A, Castro Vale I, Kleber R, Mota Cardoso R. Estudo de propriedades psicométricas do Questionário de Trauma de Infância-Versão breve numa amostra portuguesa não clínica. Laboratório de Psicologia 2013;11:103-120.

46. Maia A, McIntyre T, Pereira MG, Ribeiro E. War exposure and posttraumatic stress as predictors of Portuguese colonial war veterans' physical health. Anxiety Stress Coping 2011;24:309-325.

47. Noppe G, de Rijke YB, Dorst K, van den Akker EL, van Rossum EF. LC-MS/MS-based method for long-term steroid profiling in human scalp hair. Clin Endocrinol (Oxf) 2015;83:162-166.

48. Steudte-Schmiedgen S, Stalder T, Schonfeld S, Wittchen HU, Trautmann S, Alexander N, et al. Hair cortisol concentrations and cortisol stress reactivity predict PTSD symptom increase after trauma exposure during military deployment. Psychoneuroendocrinology 2015;59: 123133.

49. Groer MW, Kane B, Williams SN, Duffy A. Relationship of PTSD symptoms with combat exposure, stress, and inflammation in American soldiers. Biol Res Nurs 2015;17:303-310.

50. Pinna KL, Johnson DM, Delahanty DL. PTSD, comorbid depression, and the cortisol waking response in victims of intimate partner violence: preliminary evidence. Anxiety Stress Coping 2014;27:253-269.

51. Olff M, de Vries GJ, Guzelcan Y, Assies J, Gersons BP. Changes in cortisol and DHEA plasma levels after psychotherapy for PTSD. Psychoneuroendocrinology 2007;32:619-626.

52. Klaassens ER, Giltay EJ, Cuijpers P, van Veen T, Zitman FG. Adulthood trauma and HPA-axis functioning in healthy subjects and PTSD patients: a meta-analysis. Psychoneuroendocrinology 2012;37:317-331.

53. Sheerin CM, Lind MJ, Bountress KE, Marraccini ME, Amstadter AB, Bacanu SA, et al. Meta-analysis of associations between hypothalamicpituitary-adrenal axis genes and risk of posttraumatic stress disorder. J
Trauma Stress 2020 [Epub ahead of print].

54. Wang Q, Shelton RC, Dwivedi Y. Interaction between early-life stress and FKBP5 gene variants in major depressive disorder and post-traumatic stress disorder: A systematic review and meta-analysis. J Affect Disord 2018;225:422-428.

55. Hawn SE, Sheerin CM, Lind MJ, Hicks TA, Marraccini ME, Bountress $\mathrm{K}$, et al. GxE effects of FKBP5 and traumatic life events on PTSD: A meta-analysis. J Affect Disord 2019;243:455-462.

56. Bader HN, Bierer LM, Lehrner A, Makotkine I, Daskalakis NP, Yehuda R. Maternal Age at Holocaust Exposure and Maternal PTSD Independently Influence Urinary Cortisol Levels in Adult Offspring. Front Endocrinol (Lausanne) 2014;5:103.

57. Glenn DM, Beckham JC, Feldman ME, Kirby AC, Hertzberg MA, Moore SD. Violence and hostility among families of Vietnam veterans with combat-related posttraumatic stress disorder. Violence Vict 2002;17: 473489.

58. Rosenheck R Fontana A. Transgenerational effects of abusive violence on the children of Vietnam combat veterans. J Trauma Stress 1998;11: 731-742.

59. Yehuda R Bierer LM. Transgenerational transmission of cortisol and PTSD risk. Prog Brain Res 2008;167:121-135.

60. Yehuda R. Post-traumatic stress disorder. N Engl J Med 2002;346:108114

61. Suzuki A, Poon L, Papadopoulos AS, Kumari V Cleare AJ. Long term effects of childhood trauma on cortisol stress reactivity in adulthood and relationship to the occurrence of depression. Psychoneuroendocrinology 2014;50:289-299.

62. Carpenter LL, Shattuck TT, Tyrka AR, Geracioti TD Price LH. Effect of childhood physical abuse on cortisol stress response. Psychopharmacology (Berl) 2011;214:367-375. 